\title{
Correction
}

\section{Roy et al. On Two Novel Parameters for Validation of Predictive QSAR Models. Molecules, 2009, 14, 1660-1701}

\author{
Partha Pratim Roy, Somnath Paul, Indrani Mitra and Kunal Roy *
}

Drug Theoretics and Cheminformatics Lab, Division of Medicinal and Pharmaceutical Chemistry, Department of Pharmaceutical Technology, Jadavpur University, Kolkata 700 032, India;

E-Mails: partha_chemju@yahoo.co.in (P.P.R.); somnath_juph@yahoo.co.in (S.P.); indranimitra06@gmail.com (I.M.)

* Author to whom correspondence should be addressed; E-Mails: kunalroy_in@yahoo.com or kroy@pharma.jdvu.ac.in; Fax: +91-33-2837 1078.

Received: 25 January 2010 / Published: 26 January 2010

The authors wish to make the following corrections to this paper [1]:

Abstract: The sentence "The parameter $\mathrm{r}_{\mathrm{m}}{ }^{2}$ (overall) penalizes a model for large differences between observed and predicted values of the compounds of the whole set (considering both training and test sets) while the parameter $\mathrm{R}_{\mathrm{p}}{ }^{2}$ penalizes model $\mathrm{R}^{2}$ for large differences between determination coefficient of nonrandom model and square of mean correlation coefficient of random models in case of a randomization test." should read as: The parameter $\mathrm{r}_{\mathrm{m}}{ }^{2}$ (overall) penalizes a model for large differences between observed and predicted values of the compounds of the whole set (considering both training and test sets) while the parameter $\mathrm{R}_{\mathrm{p}}{ }^{2}$ penalizes model $\mathrm{R}^{2}$ for a small difference between determination coefficient of nonrandom model and square of mean correlation coefficient of random models in case of a randomization test.

Section 2.3.2.4: The sentence "We have used a parameter $\mathrm{R}_{\mathrm{p}}{ }^{2}$ [32] in the present paper, which penalizes the model $\mathrm{R}^{2}$ for the difference between squared mean correlation coefficient $\left(\mathrm{R}_{\mathrm{r}}{ }^{2}\right)$ of randomized models and squared correlation coefficient $\left(\mathrm{R}^{2}\right)$ of the non-randomized model." should read as: We have used a parameter $R_{p}{ }^{2}$ [32] in the present paper, which penalizes the model $R^{2}$ for a small difference between squared mean correlation coefficient $\left(\mathrm{R}_{\mathrm{r}}{ }^{2}\right)$ of randomized models and squared correlation coefficient $\left(\mathrm{R}^{2}\right)$ of the non-randomized model. 
Conclusions: The sentence "The parameter $\mathrm{R}_{\mathrm{p}}{ }^{2}$ penalizes model $\mathrm{R}^{2}$ for large differences between determination coefficient of nonrandom model and square of mean correlation coefficient of random models in case of a randomization test and thus confirms whether a model has been obtained by chance or not.” should read as: The parameter $\mathrm{R}_{\mathrm{p}}{ }^{2}$ penalizes model $\mathrm{R}^{2}$ for a small difference between determination coefficient of nonrandom model and square of mean correlation coefficient of random models in case of a randomization test and thus confirms whether a model has been obtained by chance or not.

\section{Reference}

1. Roy, P.P.; Paul, S.; Mitra, I.; Roy, K. On Two Novel Parameters for Validation of Predictive QSAR Models. Molecules 2009, 14, 1660-1701.

(C) 2010 by the authors; licensee Molecular Diversity Preservation International, Basel, Switzerland. This article is an open-access article distributed under the terms and conditions of the Creative Commons Attribution license (http://creativecommons.org/licenses/by/3.0/). 